\title{
Quality in Early Years Settings: Government, Research and Practitioners' Perspectives
}

\author{
Michelle Cottle and Elise Alexander
}

Roehampton University, London, UK

School of Education,

Roehampton University,

Roehampton Lane,

London

SW15 5PJ

\begin{abstract}
This article begins by outlining the UK Government policy context, offering a brief critique before moving on to summarise recent research into 'quality' in the early years. The main body of the article locates the perspectives of early years practitioners within this context, drawing on data from an Economic and Social Research Council (ESRC)funded study of eighteen early years settings, including interviews and focussed group discussions with 165 practitioners. The findings reveal that practitioners' understandings of 'quality' are influenced by Government discourses but appear to be linked to the context of their setting together their personal and professional histories. In discussing the nature of 'quality', we focus on tensions inherent in the Government discourses and draw out the implications for children's experiences and the training and development of early years practitioners.
\end{abstract}

Keywords: early years; quality; success; practitioners' perspectives

\section{Introduction}

The concept of 'quality' in early childhood services has been the subject of international debate over past decades (Dahlberg et al., 2007, p. 179, Moss, 1994, Penn, 2000, Tanner et al., 2006) not least because of the diverse perspectives of the stakeholders involved. These stakeholders include parents, practitioners (an inclusive term that we use to encompass all the people working with children in early years services), managers, politicians and, indeed, children themselves (Woodhead, 2000). This broad range of interested parties are likely to hold an equally broad range of perspectives on what constitutes 'quality' and on the primary purposes and intended benefits of early years care and education. With the advent of the Labour Government in 1997, the 'quality' debate took on particular significance. The National Childcare Strategy announced in 1998 placed early years at the heart of the 
political agenda, positioning it as a key driver for wider socio-economic aims to reduce poverty. As a result, there has been an unprecedented investment in children's services and a period of rapid reform and early years policy has increasingly come to be seen as an important area in its own right (Baldock et al., 2009). The Every Child Matters Green Paper (DfES, 2003) articulated the Government vision, emphasising 'quality' with reference to early years provision, education, care, staffing, training, leadership and 'joint-working'. This has required a multidisciplinary approach, drawing together professional teams of practitioners from a range of backgrounds and disciplines to work together in increasingly complex settings. In this context, the understandings of practitioners are highly significant. This article reviews the main elements of the Labour Government policy and offers a brief critique before summarising the current research to date. It locates and explores early years practitioners' perspectives on 'quality' within this context, drawing on findings from an ESRC-funded research project (RES-061-23-0012) carried out between January 2007 and May 2009.

\section{'Quality' in Early Years Services: the Labour Government reforms}

The Labour Government focused on 'tackling poverty', increasing partnership, integration and professionalism within early years services together with measures that were intended to narrow the existing divisions between education and care (Baldock et al., 2009). The Every Child Matters (DfES, 2003) agenda was enshrined in law by the Children Act 2004 and, together with The Ten Year Strategy for Childcare (HM Treasury, 2004), it emphasised the focus on the needs of children and their parents and coordination between the different disciplines and professions that constitute early years services. 
From 1997, funding was provided for initiatives such as Sure Start Local Programmes, Neighbourhood Nurseries and Early Excellence centres and, in 2004, a change in service delivery was announced based on these initiatives. This involved 'the reconfiguration of services around the child and family in one place' (DfES, 2004, p. 4) through Children's Centres and extended schools, based on Sure Start initiatives, and significant goals were set for 2010. Several guidance frameworks were introduced to set out expectations for the providers of early years care and education in terms of the 'quality' of their practice and provision: these were the National Standards for Under 8s Daycare and Childminding (DfES, 2000), the Curriculum Guidance for the Foundation Stage (CGFS) (DfEE/QCA, 2000) and Birth to Three Matters (BTTM) (DfES, 2002). Settings were inspected according to these standards by the Office for Standards in Education (Ofsted). The Childcare Act 2006 announced that the Early Years Foundation Stage (EYFS) (DCSF, 2007a) would come into law in September 2008 as a 'single quality framework' to supersede the CGFS, BTTM and the National Standards in guiding practice, regulation and further integrating the inspection process across all early years settings. In addition to these key developments, a National Qualifications Framework was established by the Qualification and Curriculum Authority during this period, although this did not take into account all the qualifications and training that different early years practitioners undertake.Work on a new Integrated Qualifications and Credit Framework was commissioned is currently being implemented (Owen, 2006, QCDA, 2010). Other important developments at the national level reflected the push to integrate children's services locally, for example, the Department for Education and Skills was subdivided into different departments, including the Department for Children, Schools and 
Families and Ofsted became the Office for Standards in Education, Children's Services and Skills (Baldock et al., 2009).

\section{Issues around the Government vision of 'quality'}

Throughout the documentation underpinning the significant and rapid changes above, it is interesting to note the number of times 'quality' is cited but rarely if ever defined, suggesting an assumption that there is an explicit and agreed model of what constitutes quality childcare and quality practitioners. It could be argued that the remedial nature of some of the successive guidance frameworks demonstrates that this has been problematic. The guidance was generally well received by early years practitioners at first (David, 2001, Duffy, 2006, Meade \& Cubey, 2008, Pugh, 2006), particularly in its recognition of the holistic nature of learning and the role of play. But there was soon evidence that the emphasis on cognitive outcomes in the CGFS and 'standards agenda' was having a strong impact on practice in Reception classes resulting in 'top-down' pressure to prepare children for their school future (Adams et al., 2004, Anning et al., 2009, Duffy, 2006).

The Government vision applies an evaluative definition of 'quality' without a complementary analytic or descriptive aspect which would take account of the 'distinct and unique combination of characteristics' of the services themselves (Moss, 1994). 'Quality' has attained a generic, 'common sense' status and as such is promoted though national goals, standards, targets and various quality assurance procedures in what Tanner el al. (2006, p. 6) refer to as an 'official' definition of quality predicated on it being an 'objective reality that can be defined, measured, evaluated and assured'. This 'official' definition is located within a 'discourse of quality' itself located within the dominant positivistic, exclusionary paradigm (Dahlberg et al., 2007); it 'rests on a forgetting of the exclusion practices through 
which one set of meanings has been institutionalised and various other possibilities have been marginalised' (MacLure, 2003, p. 179). It is argued that the institutionalised practices that are currently dominant in this 'official' context are those of developmental psychology (Dahlberg et al., 2007, Tanner et al., 2006) within which features of early years services are largely evaluated according to positive developmental outcomes in children. This is evidenced by the emphasis on agerelated developmental phases in the EYFS which sets out a series of learning goals that all children should attain by the age of five, legal requirements related to children's welfare and learning (DCSF, 2007c). But this appears to conflict with the non-statutory guidance which establishes principles of practice based upon children's choices and play interests (DCSF, 2007b). The statutory emphasis gives an indication of the priorities that practitioners are expected to have, leaving them to struggle with the tensions between the principled practice of working with children within a framework of policies that aim to provide flexibility and an inflexible system of prioritising targets, inspections and accountability (Anning et al., 2006). In addition, the distinction between 'childcare' and 'early education' remains, reflected in the language and constitution of Government policies and frameworks and therefore within the services themselves despite the vision of a more integrated approach (Moss, 2008). This situation is made all the more complex as it is operationalised by a workforce from a diverse range of backgrounds and disciplines with markedly unequal working conditions, pay and status. Moss describes this as a 'yawning gap' in some cases, again emphasising the 'split thinking'(2008, p. 122). It is an awareness of these tensions that formed the basis of our project. 


\section{Research into the 'quality' of children's experiences}

Sylva and Pugh (2005) discuss a body of research that illuminates the importance of early learning. They argue that this is carried out in two distinct disciplines, neurological and psychological, and that the psychological research into cultural and cognitive structures and learning dispositions is the more 'powerful' of the two (2005, p. 13). The implications of this are far-reaching, especially when considered in relation to the considerable amount of research into the effects of early education on children's readiness for school, their attainment throughout their education and even their future employment chances (Melhuish, 2004). Within this context, the concepts of 'quality' and 'success' assume immense importance.

Sylva and Pugh (2005) argue that the term 'quality' entered the debate in the discussion of findings from research based on intervention programmes carried out in the US in the 1960s and 70s, such as the High Scope/Perry Pre School Study (Schweinhart, 2002) and the Abecedarian Project (Campbell et al., 2002). Since then, approaches to defining the 'quality' of early years provision have frequently involved the examination of structures and processes in relation to child outcomes, often educational attainment or a measurable aspect of child development (Moss, 1994, Munton et al., 1995). Sylva and Pugh use longitudinal research from the US and England as evidence for the effectiveness of this approach (NICHD, 2006, Peisner-Feinberg et al., 2001) and these projects, particularly the Effective Provision of Pre-school Education (EPPE) project (Sylva et al., 2004), have contributed to the 'evidence-informed policy' of the Labour Government (Baldock et al., 2009). Indicators for evaluating the 'quality' of early years settings in this research have included ratings scales, such as the ECERS-R and the Care Giver Interaction Scale (CIS) which measure factors relating to process and structure, together with a focus on developmental outcomes. The authors of the EPPE project acknowledge that their 
study considers a setting's 'effectiveness' in relation to child development outcomes, describing effectiveness as a component of 'quality' (Sylva et al., 2004, Sylva et al., 2006) and Sylva and Roberts (2010) explore other approaches to defining quality. Sylva et al. (2006) take the view that definitions of quality practice should be relevant to the particular context of a society; for example, the ECERS-E was developed during the EPPE project as a supplement to the existing ECERS-R in order to be more sensitive to pedagogical processes and curricular goals in England (Sylva et al., 2006). But, in a review of approaches to quality, Williams (1995) concludes that while ratings scales are valuable tools they can assume a universal model of 'quality', even with adjustment to a particular society. This chimes with the 'official' approach discussed above (Tanner et al., 2006) in that scales such as these are generally devised by outside agencies, regulatory bodies or other 'experts' (Brophy \& Statham, 1994) and therefore may not reflect the values, ideals and pedagogical beliefs of the practitioners working in the settings. This seems particularly relevant considering the current emphasis on performative discourses within educational settings (Ball, 2003, Troman et al., 2007). 'Quality' is a relative, values-based and therefore subjective concept (Dahlberg et al., 2007, Pence \& Moss, 1994) and Tobin (2005) argues that quality standards are culturally constructed and should therefore be developed collaboratively through dialogue in order to ensure that they reflect local concerns. Similarly, Lilian Katz (1993) argues for a perspectives-based approach when defining quality in order to explore the meanings that those involved attribute to their experience. As there was limited evidence of the 'inside perspective' of early years practitioners' views in this respect (Katz 1993: 6), we aimed to address this through our research in order to provide further insight into the ways that practitioners operate within the current context. 
One of the main findings from the EPPE project (Sylva et al., 2004) and the associated Researching Effective Pedagogy in the Early Years (REPEY) Study (Siraj-Blatchford et al., 2002) was that settings with higher quality scores were those where staff had higher qualifications. But Adams et al (2004) have thrown up huge questions about the training of the early years workforce in England, highlighting a demonstrable gap between children's experiences in nursery and reception classes, even where the classes are situated in the same schools. Considering that practitioners in the state sector are generally trained to a higher level than those working in the private and voluntary sectors (Sylva et al., 2004, Sylva \& Pugh, 2005), if there is no consistent understanding of the CGFS (DfEE/QCA, 2000) and the purposes of early years education amongst school-based practitioners then it is unlikely that there will be a consistent understanding amongst other early years practitioners and presumably this will also extend to the EYFS (DCSF, 2007a). Adams et al. (2004) found that practitioners working in Foundation Stage Units are highly influenced by the demands of the curriculum and testing framework which impact upon their own professional knowledge about the needs of the children with whom they work. This could suggest that early years practitioners have lost confidence in their professional knowledge; they may have become reliant upon 'official' frameworks and those who enforce them to judge the 'quality' and effectiveness of their practice.

\section{The Understanding Quality project}

Our project was based on the premise that well-articulated shared understandings of 'quality' and 'success' are essential in order to bring about real improvements in children's lives and in their early learning experiences. The research questions were as follows:

- how do early years practitioners understand quality' and 'success' in the context of their particular settings? 
- how are these understandings expressed in the daily experiences of the children with whom they work?

- what are the implications of these understandings in planning for practitioners' professional development?

We adopted a broadly symbolic interactionist approach (Schwandt, 1998) using a range of data collection methods (in-depth interviews, focused discussions, observations of and consultations with children) to address the research questions. This approach allowed us to gain insights into how meanings and shared values were constructed amongst practitioners. Data were collected from eighteen early years settings across two London boroughs and two shire counties between May 2007 and March 2008; these included nursery schools and classes, reception classes, freestanding nurseries and Children's Centres (See Table 1). Whilst not claiming that the sample was in any way representative, the selection of a range of socio-economic contexts, which included inner city, outer city, suburban and rural localities and inhabited by ethnically diverse communities, was intended to ensure that the analysis took account of the specificities of local contexts. Settings were recruited through the recommendations of local authorities, Higher Education colleagues and professionals working in the field based upon their own indicators of good practice.

-(Insert Table 1)

Perspectives were sought from 165 practitioners through the interviews and focus groups (See Table 2). We interviewed the head of centre or head teacher in every setting and also practitioners in various roles and at each level of seniority, negotiating which individuals could be interviewed with each setting. 
Interviews were designed to gather information about practitioners' professional histories and values (supplemented by a biographical questionnaire), their understandings of the contexts of the settings (structure, aims and purposes) and their perspectives on 'quality' and 'success', which included an exploration of their ideals, aspirations, inspirations and constraints. The focused discussions involved group activities and discussions about the concepts of 'quality' and 'success' in early years settings and also provided us with the opportunity to observe relationships and interactions and to draw inferences about the way the staff group worked together. Implicit understandings were investigated through environmental observations and documentary analysis of policies and procedures.

Although the main focus of the project was on the meanings that early years practitioners construct, we considered it important to observe and consult children to investigate the ways in which practitioners' values and understandings were expressed in the children's experience. We conducted 70 individual child observations using the Target Child method (Sylva et al., 1980). Each child was selected at random by the research team and was observed for periods between 30 minutes and one hour and we also undertook some limited consultations with individual and groups of children.

In the later stages of the project a workshop was held to which participating practitioners and members of the project advisory panel were invited. The purpose of this event was in part to disseminate findings relating to earlier stages, and also to further probe data pertaining to the implications of practitioners' understandings of quality for staff training and professional development. Data were collected through discussion and activities focusing on staff recruitment, development and related issues. 


\section{Ethical issues}

There were two particular ethical issues in this investigation. The first concerns researching with and around young children. Informed consent was obtained from the children's parents as a matter of course but given the age of the children, not formally from the children themselves. Instead we sought their assent, paying careful attention to their facial expressions, body language and utterances, so if they showed any sign of not wishing to be involved, we stopped at once (Eide \& Winger, 2005). The second issue concerns the rights and feelings of the participating practitioners (Denscombe, 2002). The purpose of the research was explained to all participants and their informed consent was obtained. The aim of the investigation was not to evaluate practitioners' ways of thinking about 'quality' but rather to explore these and to consider the impact of existing constraints, assumptions and practices on their professional understandings. Because of the potential sensitivity of this investigation, particular care was taken to protect the identity of participants and to anonymise the settings.

\section{Analysis}

Transcripts were coded and analysed to identify emerging themes using the constant comparison method and then compared using a series of matrices in a process of cross-case analysis (Miles \& Huberman, 1994). The data were analysed using frameworks derived from classic studies of children's learning (Isaacs, 1932), Government documents focusing on children's learning (DCSF, 2007a, DES, 1990, DfEE/QCA, 2000) and also a synthesis of research about children's learning (Ball, 1994, Sylva et al., 2004). From these a series of analytic lenses was devised that allowed us to gain insights into practitioners' understandings of 'quality' in terms of their aspirations for children. A framework for defining 'quality' devised by Tanner at al. (2006) was helpful in illuminating the priorities of the settings as it takes 
account of both objective and subjective understandings of 'quality' through a continuum model (see figure 1). Tanner et al. propose that fixed official determinants such as targets, standards and outcomes are at one end of this continuum and local definitions of quality which are shaped by the particular context, values and beliefs of practitioners or groups of practitioners are at the other end, and are dynamic and contested.

-(Figure 1)

We drew on Maclure's (2003) discussion of discourse analysis to help us to recognise how values and practices are fixed and delineated within group cultures. MacLure (2003) argues that conceptions that appear self-evident can be unravelled or 'disarticulated' by paying close attention to underlying identities, values and concepts. In addition, Goodson (2003, p. xiii) argues that 'the growing understanding of teachers' beliefs, motivations and missions provides a new way of exploring some of the misconceptions and misapplications that can be found at the heart of some of the new initiatives aimed at restructuring our schools'. His commentary on the impact of change and reform on professional understandings and identities has helped with this process of disarticulation.

\section{Practitioners' perspectives}

The findings below have been structured according to the themes related to our research questions:

- the nature of 'quality'

- children's experiences

- the 'right' staff

- $\quad$ artnership with parents 
We have included an additional theme (partnership with parents) because practitioners spoke of 'quality' largely in terms of relationships with parents and the wider community as well as with the children and each other.

\section{The nature of 'quality'}

Our data did not yield a precise definition of 'quality' being utilised by practitioners. They were all influenced by 'official' discourses to some extent but there were different ways of understanding 'quality': as a dynamic process, as an aspiration, something to be achieved but essentially static, or somewhere between the two (Tanner et al., 2006). Interpretations of 'quality' seemed to be linked to the context of the setting and practitioners' personal and professional histories.

\section{The influence of 'official' discourses}

Practitioners frequently commented upon the elusive nature of 'quality' using terms such as 'slippery', 'atmosphere', 'ethos', a 'feel', something that is 'hard to see because you are involved in it'. That it was also 'hard to prove' and could not be written on a piece of paper indicated some of the pressure that they felt in having particular practices prescribed by the government. Ofsted inspections and children's attainments against the EYFS (or then CGFS) Profiles were discussed in all settings but these were not always considered the main indicator of the 'quality' of the setting. Ofsted was broadly considered to be the stamp of 'quality' in two of the schools ( $\mathrm{St}$ Faith's and Meadowview) and two of the Children's Centres (Brackenridge and Vale) who could therefore perhaps be positioned more towards the 'official approach' on the continuum (see Figure 1); in these settings most of the practitioners tended to talk about 'quality' in terms of external indicators. Practitioners in the other settings considered Ofsted outcomes as important but not an end goal although it was 
interesting to see how the language of audit and accountability had been incorporated into the professional discourse.

I think you've got to be self-evaluating and reflective, obviously you've got to know your material but you've also got to audit yourself all the time against excellence. (Lowood Children's Centre, Head)

Practitioners at the two other schools in our sample expressed frustration at the power of the current outcomes-based agenda which conflicted with their own professional values:

We believe that some of the targets and expectations for young children are totally inappropriate. So there's a constant juggling of needing to fulfil certain requirements but stay true to what we believe as well. (Edgehill School, Reception Teacher)

In discussing what she and her colleagues believed quality practice to be, the teacher above cited a focus on children's emotional development within an informal environment, avoiding reward systems in their feedback favour of 'learning conversations'. The headteacher corroborated this in her discussion of the 'bottom up' model that she had envisaged for the school when she came to the job, stating that 'when you go into our Year 6 classrooms and you watch how they operate, they're not a million miles away from how children are organised in the nursery setting'; the research team were not able to explore this opportunity due to time constraints. She promoted individual approaches to learning accompanied by respectful collaboration but acknowledged that this clashed with the accountability regime:

We're not systems driven, we're very much a learning-centred school not a performanceoriented one and that's a discussion we keep having to come back to with governors and with, which we will I'm sure with Ofsted inspectors when they arrive in the next few weeks. (Edgehill School, Headteacher)

There was a sense of a group culture in Edgehill School which did not seem to be as developed at Downside School where the Foundation Stage Leader described an individual struggle, emphasising a moral dimension (Goodson, 2003).

I think the problem is we are very results driven, and parents want to see things on paper; Ofsted inspectors want to see things on paper, so in that sense it is kind of changing the 
whole culture of education and...the way it is. I think it is shifting to an extent - there are some things changing, but I don't there's enough. I suppose it's about sort of having guts in a way to shift it further and some people are doing it, but, I don't know, I think it'll probably take a long time. (Downside School, Reception Teacher)

Three Children's Centre heads (Northfield, Churchill and Queens) expressed strong resistance to Ofsted standards despite having received 'Good' grades in recent inspections. One could argue that they may have felt differently had they achieved 'Outstanding' but all three expressed their disagreement in emotional terms citing their professional values, which were again based around relationships and attitudes to learning. This relates to Goodson's (2003, p. 132) concept of 'principled professionalism' which positions the work that practitioners do as a moral and ethical vocation. Osgood (2006: 8) agrees, arguing that practitioners are self-regulated by internal constructions of their professionalism, an 'ethic of care' which runs counter to the dominant performative discourses, particularly the externally prescribed standards against which practitioners must measure their competence, and thus creates tensions for practitioners. They spoke of their efforts to protect their staff and children, demonstrating what Hoyle and Wallace (2007) would term 'principled infidelity':

I think that whole outcomes driven thing is hugely damaging and I find myself playing two games. I play one for Ofsted and I play another which suits my philosophical viewpoint. So I have developed mechanisms whereby my staff can actually respond to that whole outcomes debate. We do it...I hope in a way that does not pervade what we do week on week..... we take the data from snapshots that we take... three times a year to actually inform us in terms of being able to have the conversation with the school improvement partner, with Ofsted, but actually we refuse to be driven by that...because life is much more than that. Children are too valuable for that. (Northfield Children's Centre, Head of Centre)

A similar attitude was evident to varying degrees in other centres where positive Ofsted judgements were sometimes seen as a 'necessary evil' in order to achieve goals perceived as more important; for example one Children's Centre Head felt they could become a stronger 'voice' within the local authority as a result. 


\section{The dynamic nature of 'quality'}

Some practitioners framed 'quality' as an evolutionary process, one that requires

reflection and constant questioning.

After Ofsted I said, "Just have a rest for a while," and then next week they were coming in with new ideas of what they wanted to try...they never stand still and although they've been here, a lot of them, for quite a long time, which provides that sort of stability and continuity in the school, they're not afraid to change their practice, as they say, to challenge themselves and to move things on. (Emanuel Children's Centre, Head of Centre)

We observed a particular culture of debate or 'positive dissensus' (Mac Naughton, 2005) in this Children's Centre together with three others (Churchill, Rosewood and Stockton) where practitioners would identify problems, working through differences and attuning themselves to local needs through dialogue and discourses of reconstruction (Billett et al., 2007, Mahony \& Hextall, 2000). This was most evident during the focus groups where practitioners constructed, deconstructed and reconstructed their understandings as a group (Cottle, 2008), for example practitioners at Rosewood Children's Centres deliberated policy concepts such as 'inclusion', considering what it 'looked like' in their setting by exploring each other's perspectives and experiences. One explanation for this culture of debate might be that these settings were in various stages of transition and were accustomed to thinking about change in many aspects of their work. Another could be that leaders foster a culture in which contest and argument are viewed as healthy in pursuit of 'quality', as was observed in two of the four centres mentioned above, but further research is necessary to investigate how cultures develop in complex early years organisations.

Many practitioners considered 'quality' to be something that emerges or evolves as they put their professional values into practice.

We're not just paying lip service to a set of principles that have been laid out in some curriculum document somewhere. It's got to come from your own needs, wants and desires for those children. (Queens Children's Centre, Head of Centre) 
These less tangible indicators suggested that each practitioner had personal templates

for 'quality' which were composed from experiences of working with children.

I think it has changed as I have changed jobs and done different things actually, it's very much an evolving thing I think. Working in a children's home was very emotional and very challenging, working with children with severe behavioural problems. Then working in a private day nursery was a great opportunity to do my NVQ but then when I moved from there to here I can see that there were lots of things that I felt were fine practice but perhaps not really, really good practice. It's probably since being in a nursery school that I've learned the most about what I perceive early years to be. So it changes all the time, as I learn more, it changes. (Northfield Children's Centre, Teacher)

For this practitioner, 'good practice' was based around her efforts to build trusting relationships with the children and their families and affording children the time, space and choices to develop their own independence whilst they were in the setting. As is evident from the quote above, she felt that she had benefited from the 'cumulative effect' of her experiences and training but she also viewed the different perspectives of her colleagues as incredibly important, even inspiring. She valued relationships with her colleagues but also discussed practitioners she had worked with in the past, appreciating insights different professional backgrounds . Personal definitions frequently arose from relationships between the practitioners and many mentioned a key figure or mentor. In three of the settings (Stockton and Emanuel Children's Centres and Nesbit Nursery) the current head was regarded as inspirational and supportive and staff stated that they felt valued and largely attributed it to this person. However many of the mentor figures mentioned related back to the beginning of practitioners' careers, as this practitioner demonstrates in reflecting back on the beginning of this, her first position.

When I first came here I met one of the girls I work with, she was at the Drop-In at the time, and...it was how she worked, I knew that I wanted to be like that... She was really good with the parents, the children. She was firm but kind and it was just in general... she always knew what to say to the children, to the parents and she managed to ...you know if there was a problem to calm it down. She always got the right things for them to play. (Rosewood Children's Centre, Learning Support Assistant)

Goodson (2003) argues for a need to accord dignity and status to the practical knowledge that people possess. He advocates 'a self-directed search and struggle for 
continuous learning related to one's own expertise and standards of practice' (2003, p. 132) as part of a re-appropriation of professionalisation, important in this current climate where the technical aspects of professionalism are frequently emphasised over 'professional biography'.

\section{Children's experiences}

Practitioners in all the settings demonstrated their commitment to the children's welfare, development and learning through warm, positive relationships with children and we had no doubts about their sincerity. Without positive relationships founded on mutual trust, shared values and a common purpose, practitioners said that quality provision was impossible. Practitioners frequently said that children's activities should be based upon children's interests, and that the role of the practitioner was to observe, extend and support child-initiated play agendas but we found that the many of the interactions with children were for managerial or monitoring purposes. In 70 Target Child observations, we found 52 instances of what could be termed 'sustained shared thinking' (Sylva et al., 2004) between children and adults, in contrast to 298 instances of short, managerial interactions ('do your coat up'; ‘please don’t run...'). Only two of the sustained complex interactions took place in school-based settings, with the remaining 50 occurring in Children's Centres or nurseries, suggesting that opportunities for sustained shared thinking seem to occur more readily in Children's Centres and nurseries than in school-based settings. While the EPPE report (Sylva et al., 2004) recommends a balance of adult and child-initiated activities, practitioners in Children's Centres appeared to place more value on supporting child-initiated activities and practitioners in Reception classes appeared to place more value on adult-led activities, in some cases leaving child-initiated activities until everything else had been completed. We suggest that these differences are rooted in the contexts 
of the settings and perhaps in the cultural differences between the professional identities of teachers, particularly those who work or have worked in schools, where it seems impossible to resist the 'regulatory gaze' (Osgood, 2006, p. 5), and other early years practitioners working in settings that may be considered 'marginal institutions' such as day centres and nurseries (Taggart, forthcoming). Teachers in Foundation Stage Units found it difficult to avoid the pressure to prepare children for later stages of education or the expectations of colleagues in Key Stage 1 which has an impact upon their professional identity, as can be seen here.

I think it's awareness of where they've got to be... I feel as a teacher, if I don't get them ready for that, then I've let them down. Now some of those children aren't ready and there's nothing I can do to help them, it'll come but they're not there. I guess it filters through doesn't it? I mean if they are struggling in Year 2, we didn't get them set up for it in Reception. So I guess it ripples down. There's not particular person saying, "You have to get them up to this point", it's the climate we live in. (Meadowview School, Reception Teacher)

Practitioners in Children's Centres and freestanding nurseries, on the other hand, tended to discuss different constructions of children that were removed from the managerial paradigm and we frequently observed evidence of this in their practice.

Children have individual passports, do you know what I mean? Every child is different being able to go on from wherever they are is a success criteria of their early years and there's no kind of blueprint, I think. (Focus group, Caroline Nursery School)

In our study, these practitioners tended to see their work in terms of providing rich experiences for children, in building confidence and independence and, particularly in Children's Centres, for making up for perceived deficiencies of children's lives, which is of course an element of their remit (DCSF, 2009) and an area deserving further research. 


\section{The 'right' staff}

Practitioners frequently expressed the importance of having 'quality' staff. They viewed qualifications as key, in line with Government policy, but also expressed misgivings about views of these as an absolute guarantee of 'quality'.

P3: $\quad$ I think qualified staff is quite important (Other Ps agree)

P2: $\quad$ But you can have the most qualified person in the world and they wouldn't be right for the place.

P3: $\quad$ Maybe it should be knowledge then. Knowledge...

P4: Knowledgeable staff.

P2: No I think qualified is really important but...

P3: I know what you're saying, you could be qualified but rubbish.

P4: And you can get sometimes someone who is not qualified and are...

P3: Really good.

P4: Absolutely superb and a natural with children and makes children feel...you know valued.

P3\&4: (speaking almost simultaneously) Qualified, knowledgeable staff.

(Extract from the Focus Group, Rosewood Children's Centre)

The relationships between staff teams were viewed as a critical element, reflected in the priority given in some settings to the induction of new staff. Ongoing professional development was viewed as essential to 'quality' in all settings, with practitioners often linking this to identity, both individually and as a team. However, there appeared to be a lack of confidence in the initial training of childcare workers, with at least three of the participating Children's Centres declining to recruit newly-qualified staff at NVQ Levels 2 and 3 (CWDC, 2009). This practice, if it becomes widespread, could lead to a divided workforce, with experienced, well-qualified staff employed exclusively by well-funded Children's Centres and less qualified, less experienced practitioners staffing private day nurseries and less well-funded settings. Two other Children's Centres were selective about which training providers they use, a finding that raises questions about the inequities of initial training. Our interview data revealed concerns about the academic capability of newly-qualified practitioners, 
notably that some are unable to write well enough to complete the requisite reports and observations on children. In one Children's Centre in our sample, all practitioners were expected to write their own reports. Support was provided to enable them to do so but this was a drain on time and limited resources. The issue of social class is significant here. As Osgood (2008) points out, working class practitioners, who make up the majority of the early years workforce and are qualified to the equivalent of NVQ level 2 and 3, are inherently disadvantaged in terms of their professional identity by the essentially middle class discourses and values that shape and define early years policy and practice.

Status was an issue that came up time and again in our data with practitioners experienced in childcare and early years provision expressing dissatisfaction with the perceived higher professional status of teachers. Some were conscious that teachers may not know as much about young children or playful learning (Broadhead, 2004) as they do, and yet the teachers are deemed as more competent and essential for quality provision (Sylva et al., 2004). This difference also manifested itself as a lack of confidence with nursery nurses and teaching assistants expressing their feeling that there are certain duties and roles that they cannot carry out in their work because they do not have the skills, or because they are not teachers. Whether they actually have these skills is a moot point; that they perceive that they have not is deskilling and demotivating and the introduction of teachers into all early years settings by 2010 may ultimately lead to the loss of experienced practitioners..

\section{Partnership with parents}

An important element of the EYFS is the increased focus on partnership with parents (Baldock et al., 2009) and practitioners in all settings felt that these partnerships were 
crucial for 'quality' but our data suggest that differing priorities in the settings

resulted in these partnerships being understood in different ways.

What does it look like for different people....because what it looks like for us may be very different for that family who needs that support, whatever that might be, so how do you set up the conversation, the discussion about meeting their needs? Is it our needs, in terms of what we want to see as 'success' or is it now the focus on other people's needs and how successful we’ve been? (Queens Children's Centre, Focus Group)

Broadly speaking, Children's Centre practitioners and nurseries seemed to see partnerships with parents as symbiotic and intrinsic to their work with children and talked about knowing parents very well. Practitioners in all the different settings used the term 'open door policy' but, although many Children's Centres and nurseries offered parents unlimited access to the setting, in schools there were demarcated times and places when parents were allowed in and practitioners in these settings more frequently talked about partnerships in terms of providing information in a transmission model (Epstein \& Saunders, 2002). The power relations were more implicit in other settings and some practitioners struggled with this:

I think it is probably very true that partnership is not always equal, and...I think that yes that's a tricky one in lots of ways isn't it? I think that respecting the parent... and perhaps being aware of the inequality... At the end of the day, often I think institutions do have the power don't they? I think it would be dealing really sensitively with issues, with parents so that they do feel empowered perhaps and included unless it's sort of outweighed by the power of the institution and the establishment.

(Stockton Children's Centre, Teacher)

The issues around parent partnership are complex (Crozier, 2000, Crozier \& Reay, 2005, Pugh \& Duffy, 2006) and will be dealt with in another paper.

\section{Conclusion}

Our data, although drawn from a small sample, reveal inequities in children's experience and suggest that urgent attention should be paid to initial training and issues of status in early years settings. Although there was no question that 'official' Government discourses influenced the understandings of the practitioners' involved the Understanding Quality project, their own definitions of 'quality' were rarely static 
and seemed to be linked to the particular context of their setting together with their personal and professional histories (Goodson, 2003). Their principles and professional values relating to enabling children's interests and the non-statutory guidance in the EYFS clashed to varying degrees with the system of targets also represented by the EYFS. Tensions emanated from the different priorities of settings with practitioners in Children's Centres and nurseries largely focusing on creating experiences for the children based on play whilst those in school settings, particularly Reception classes, frequently struggled with the pressure to prepare children for the rigours of Key Stage 1. These tensions appear to have been exacerbated by the contradictory nature of Labour Government policy which values the individual experiences of young children and their families on the one hand whilst prioritising standards and accountability on the other (Anning et al., 2006). We are not suggesting that standards should be abandoned but that this 'official' discourse is only one way to understand 'quality' which is a multi-dimensional, value-laden concept. Perhaps standards could more effectively be viewed as a useful starting point, allowing for a more pluralistic approach, one that is collaborative and sensitive to local differences (Tanner et al., 2006, Tobin, 2005). However, the situation seems unlikely to change as the Coalition government has committed itself to stricter Ofsted targets for schools, releasing those that achieve an 'outstanding' judgement from routine inspections, although there is little reference to other types of setting (DES, 2010). Labour Government policy may have been informed by research such as the EPPE project (Sylva et al., 2004) but the authors of this project acknowledge that 'quality should not be assessed solely on the basis of effectiveness or at the expense of other aspects of quality' (Sylva et al., 2006, p. 89). The combination of 'official' assessments of effectiveness that are sensitive to the nature of local contexts (Moss 
1994) and the personal templates of practitioners and other stakeholders may go some way towards explaining the elusive nature of 'quality' as part of an inclusive culture of debate. This would involve the constant interrogation of the values and beliefs of all involved through a process of critical and reflective dialogue in order to make informed decisions on the ways that high quality services can be provided to children and their families.

\section{Notes on contributors}

Michelle Cottle is a Senior Lecturer in Early Childhood Studies at Roehampton University. Her research interests include children's learning experiences and their participation in research, quality in the early years and Children's Centre development.

Elise Alexander is Principal Lecturer in Early Childhood Studies at Roehampton University. Her research interests include professional development in early years settings, educational policy and its translation into practice and quality in the early years.

\section{References}

Adams, S., Alexander, E., Drummond, M. J. \& Moyles, J. (2004) Inside the foundation stage: Recreating the reception year, (London, Association of Teachers and Lecturers).

Anning, A., Cottrell, D., Frost, N., Green, J. \& Robinson, M. (2006) Developing multi-professional teamwork for integrated children's services: Research, policy and practice, (Maidenhead, Open University Press).

Anning, A., Cullen, J. \& Fleer, M. (2009) Early childhood education: Society and culture, (2nd edn) (London, SAGE).

Baldock, P., Fitzgerald, D. \& Kay, J. (2009) Understanding early years policy, (2nd edn) (London, Sage).

Ball, C. (1994) Start right: The importance of early learning, (Coventry, Royal Society for the encouragement of Arts, Manufactures \& Commerce).

Ball, S. (2003) The teacher's soul and the terrors of performativity. Journal of Education Policy, 18(2), 215 - 228.

Billett, S., Ovens, C., Clemans, A. \& Seddon, T. (2007) Collaborative working and contested practices: Forming, developing and sustaining social partnerships in education. Journal of Education Policy, 22(6), 637-656.

Broadhead, P. (2004) Early years play and learning : Developing social skills and cooperation (London, Routledge Falmer).

Brophy, J. \& Statham, J. (1994) Measure for measure: Values, quality and evaluation, in: P. Moss \& A. R. Pence (Eds) Valuing quality in early childhood services: New approaches to defining quality. London, Paul Chapman), 61-75.

Campbell, F. A., Ramey, C. T., Pungello, E., Sparling, J. \& Miller-Johnson, S. (2002) Early childhood education: Young adult outcomes from the abecedarian project Applied Developmental Science, 6(1), 42-57. 
Cottle, M. (2008) Organising children's centres: Issues and challenges, paper presented at the British Educational Research Association Annual Conference, City, 3rd - 6th September 2008.

Crozier, G. (2000) Parents and schools: Partners or protagonists?, (Stoke on Trent, Trentham Books).

Crozier, G. \& Reay, D. (Eds.) (2005) Activating participation: Parents and teachers working towards partnership, (Stoke-on-Trent, Trentham Books).

Cwdc (2009) Qualifications list for those delivering the early years foundation stage. Available online at: www.cwdcouncil.org.uk/qualifications-list (accessed 30th April 2009).

Dahlberg, G., Moss, P. \& Pence, A. R. (2007) Beyond quality in early childhood education and care: Languages of evaluation, (2nd edn) (London, Routledge).

David, T. (2001) Curriculum in the early years, in: G. Pugh \& B. Duffy (Eds) Contemporary issues in the early years: Working collaboratively for children. 3rd ed. (London, SAGE Publications), 55-65.

Dcsf (2007a) Early years foundation stage: Setting the standards for learning, development and care for children from birth to five. IN Department for Children Schools and Families (Ed.) Every Child Matters, change for children. Nottingham, London, DCSF.

Dcsf (2007b) Practice guidance for the early years foundation stage: Setting the standards for learning, development and care for children from birth to five. IN Department for Children Schools and Families (Ed.) Nottingham, London, DCSF.

Dcsf (2007c) Statutory framework for the early years foundation stage: Setting the standards for learning, development and care for children from birth to five. IN Department for Children Schools and Families (Ed.) Nottingham, London, DCSF.

Dcsf (2009) The history of sure start children's centres. Available online at: http://www.dcsf.gov.uk/everychildmatters/earlyyears/surestart/surestartchildre nscentres/history/history/ (accessed 15 July 2009).

Des (1990) Starting with quality (the rumbold report). IN Department for Education and Science (Ed.) London, London, Her Majesty's Stationery Office.

Des (2010) The importance of teaching the schools white paper 2010. IN Department for Education (Ed.) London, DES.

Dfee/Qca (2000) Curriculum guidance for the foundation stage. IN Department for Education and Employment/Qualifications and Curriculum Authority (Ed.) London, London, DfEE/QCA.

Dfes (2000) National standards for under 8s day care and childminding. IN Department for Education and Skills (Ed.) London, London, DfES.

Dfes (2002) Birth to three matters: A framework for supporting children in their earliest years. IN Department for Education and Skills (Ed.) London, London, DfES.

Dfes (2003) Every child matters. IN Department for Education and Skills (Ed.) Cm ; 5860. London, London, DfES.

Dfes (2004) Every child matters: Change for children. IN Department for Education and Skills (Ed.) DfES ; 1081/2004. London, London, DfES.

Duffy, B. (2006) The curriculum from birth to six, in: G. Pugh \& B. Duffy (Eds) Contemporary issues in the early years. 4th ed. (London, SAGE), 79-92. 
Eide, B. J. \& Winger, N. (2005) From the children's point of view: Methodological and ethical challenges, in: A. Clark, P. Moss \& A. Kjørholt (Eds) Beyond listening : Children's perspectives on early childhood services. Bristol, UK, Policy), 71-90.

Epstein, J. L. \& Saunders, M. G. (2002) Family, school and community partnerships, in: M. Bornstein (Ed.) Handbook of parenting vol 5: Practical issues in parenting. 2nd ed. (London Lawrence Erlbaum Associates).

Goodson, I. (2003) Professional knowledge, professional lives: Studies in education and change, (Maidenhead Open University Press ).

Hm Treasury (2004) Choice for parents, the best start for children: A ten year strategy for childcare. London, HMSO.

Hoyle, E. \& Wallace, M. (2007) Educational reform: An ironic perspective. Educational Management Administration \& Leadership, 35(1), 9-25.

Isaacs, S. (1932) The children we teach, (London, University of London Press Ltd).

Katz, L. G. (1993) Multiple perspectives on the quality of early childhood programmes. European Early Childhood Education Research Journal, 1(2), 59.

Mac Naughton, G. (2005) Doing foucault in early childhood studies: Applying poststructural ideas, (Abingdon, Routledge).

Maclure, M. (2003) Discourse in educational and social research (Buckingham Open University Press).

Mahony, P. \& Hextall, I. (2000) Reconstructing teaching: Standards, performance and accountability, (London, Routledge Falmer).

Meade, A. \& Cubey, P. (2008) Thinking children: Learning about schemas, (Maidenhead, Open University Press).

Melhuish, E. C. (2004) A literature review of the impact of early years provision on young children, with emphasis given to children from disadvantaged backgrounds. prepared for the National Audit Office,. Institute for the Study of Children, Families \& Social Issues, Birkbeck, University of London.

Miles, M. B. \& Huberman, A. M. (1994) Qualitative data analysis : An expanded sourcebook, (2nd edn) (London, Sage).

Moss, P. (1994) Defining quality: Values, stakeholders and processes, in: P. Moss \&

A. Pence (Eds) Valuing quality in early childhood services : New approaches to defining quality. London, Paul Chapman), 1-9.

Moss, P. (2008) The democratic and reflective professional: Rethinking and reforming the early years workforce, in: L. Miller \& C. Cable (Eds) Professionalism in the early years. London, Hodder Education).

Munton, A. G., Mooney, A. \& Rowland, L. (1995) Deconstructing quality: A conceptual framework for the new paradigm in day care provision for the under eights. Early Child Development and Care, 114(11-23.

Nichd (2006) The nichd study of early child care and youth development (seccyd): Findings for children up to age 4 1/2 years, . IN National Institute of Child Health and Human Development (Eunice Kennedy Shriver) (Ed.) Washington, DC: U.S. Government Printing Office. , Washington, DC: U.S. Government Printing Office.

Osgood, J. (2006) Deconstructing professionalism in early childhood education:

Resisting the regulatory gaze. Contemporary Issues in Early Childhood, 7(1), 5-14.

Osgood, J. (2008) Narratives from the nursery: Negotiating a professional identity. London Metropolitan University 
Owen, S. (2006) Training and workforce issues in the early years, in: G. Pugh \& B. Duffy (Eds) Contemporary issues in the early years : Working collaboratively for children. 4th ed. (London, SAGE Publications), 183-194.

Peisner-Feinberg, E. S., Burchinal, M. R., Clifford, R. M., Culkin, M. L., Howes, C., Kagan, S. L. \& Yazejian, N. (2001) The relation of preschool child-care quality to children's cognitive and social developmental trajectories through second grade. Child Development, 72(5), 1534-1553.

Pence, A. \& Moss, P. (1994) Towards an inclusionary approach in defining quality, in: P. Moss \& A. Pence (Eds) Valuing quality in early childhood services : New approaches to defining quality. London, Paul Chapman).

Penn, H. (2000) Early childhood services: Theory, policy and practice, (Buckingham [England] ; Philadelphia, PA, Open University Press).

Pugh, G. (2006) The policy agenda for early childhood services, in: G. Pugh \& B. Duffy (Eds) Contemporary issues in the early years. 4th ed. (London, SAGE), 7-20.

Pugh, G. \& Duffy, B. (2006) Working with parents, in: G. Pugh \& B. Duffy (Eds) Contemporary issues in the early years. 4th ed. (London, SAGE), 151-162.

Qcda (2010) Qualifications and credit framework ( $q c f)$. Available online at: http://www.qcda.gov.uk/qualifications/60.aspx (accessed 29 October 2010).

Schwandt, T. (1998) Constructivist, interpretivist approaches to human enquiry, in: N. K. Denzin \& Y. S. Lincoln (Eds) The landscape of qualitative research: Theories and issues. Thousand Oaks, CA, Sage).

Schweinhart, L. J. (2002) How the highscope perry preschool study grew: A researcher's tale, . Phi Delta Kappa Center for Evaluation, Development, and Research. Research Bulletin 32.

Siraj-Blatchford, I., Sylva, K., Muttock, S., Gilden, R. \& Bell, D. (2002) Researching effective pedagogy in the early years (repey),. Report for DfES, HMSO (London ).

Sylva, K., Melhuish, E., Sammons, P., Siraj-Blatchford, I. \& Taggart, B. (2004) The effective provision of pre-school education (eppe) project: Findings from preschool to end of key stage 1, (London Sure Start).

Sylva, K. \& Pugh, G. (2005) Transforming the early years in england. Oxford Review of Education, 31(1), 11-27

Sylva, K. \& Roberts, F. (2010) Quality in early childhood education: Evidence for long-term effects, in: G. Pugh \& B. Duffy (Eds) Contemporary issues in the early years. 5th ed. (London, SAGE), 47-62.

Sylva, K., Roy, C. \& Painter, M. (1980) Childwatching at playgroup and nursery school, (Ypsilanti, Mich., High/Scope Press).

Sylva, K., Siraj-Blatchford, I., Taggart, B., Sammons, P., Melhuish, E., Elliot, K. \& Totsika, V. (2006) Capturing quality in early childhood through environmental rating scales. Early Childhood Research Quarterly, 21(1), 76-92.

Taggart, G. (forthcoming) Don't we care? : The ethics and emotional labour of early years professionalism. Early Years, 31(1).

Tanner, E., Welsh, E. \& Lewis, J. (2006) The quality-defining process in early years services: A case study Children \& Society 20(1), 4-16.

Tobin, J. (2005) Quality in early childhood education: An anthropologist's perspective. Early Education \& Development, 16(4), 421-434.

Troman, G., Jeffrey, B. \& Raggl, A. (2007) Creativity and performativity policies in primary school cultures. Journal of Education Policy, 22(5), 549-572. 
Williams, P. (1995) Making sense of quality: A review of approaches to quality in early childhood services, (London, National Children's Bureau).

Woodhead, M. (2000) Towards a global paradigm for research into early childhood, in: H. Penn (Ed.) Early childhood services : Theory, policy and practice. Buckingham [England] ; Philadelphia, PA, Open University Press), 7-14. 